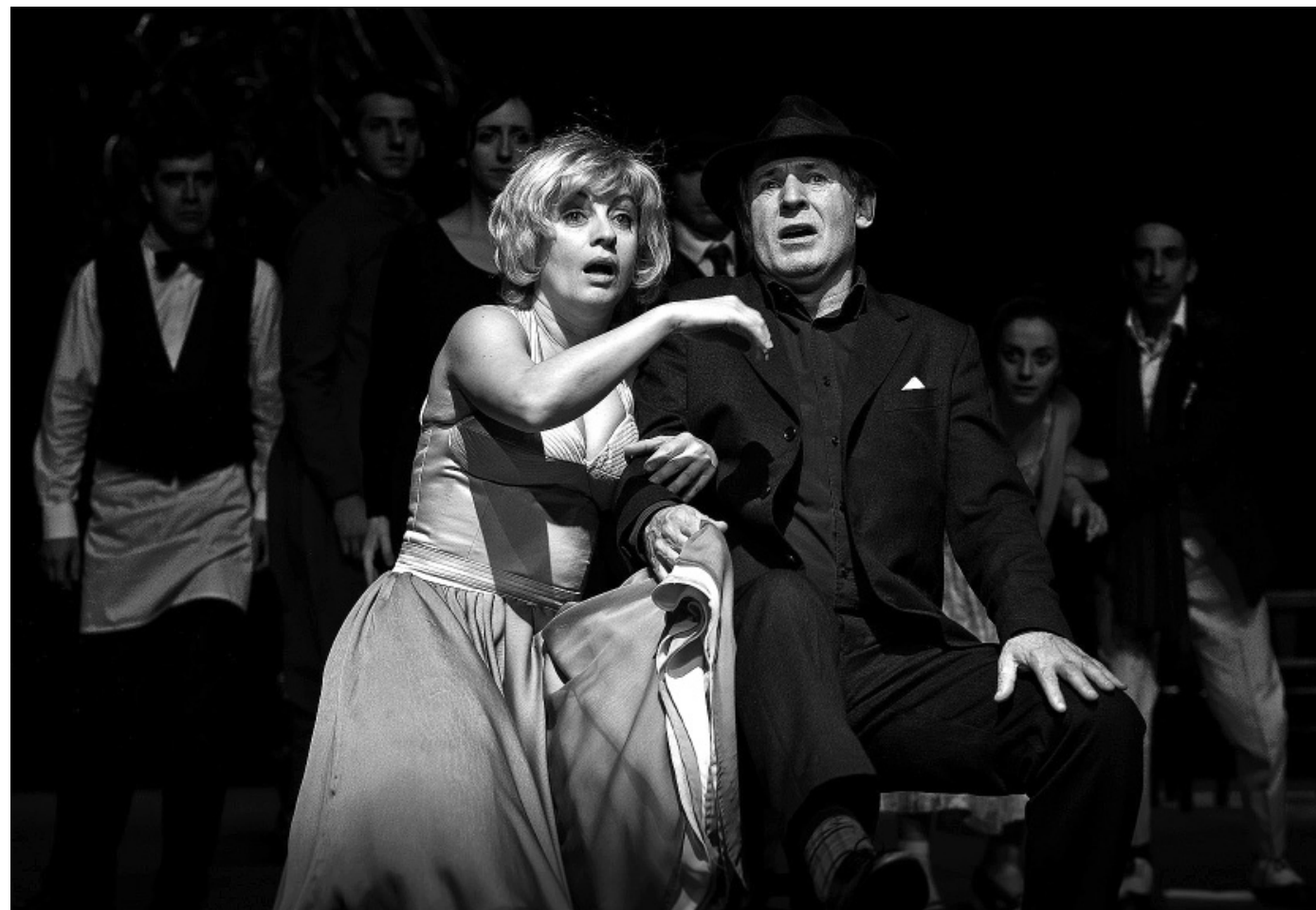

\title{
Almada ingénuo, exactamente
}

\section{Constança Carvalho Homem}

Titulo: Exactamente Antunes (2011, a partir de Nome de Guerra, 1925, de José de Almada Negreiros). Autor: Jacinto Lucas Pires. Encenação: Cristina Carvalhal, Nuno Carinhas. Cenografia e Figurinos: Nuno Carinhas. Desenho de som: Francisco Leal. Desenho de luz: Nuno Meira. Preparação vocal e elocução: João Henriques. Interpretação: Joana Carvalho, João Castro, Jorge Mota, José Eduardo Silva, Lígia Roque, Mané Carvalho, Paulo Freixinho e Paulo Moura Lopes. Produção: TNSJ. Local e data de estreia: Teatro Nacional São João, Porto, 17 de Março de 2011.

A adaptação de uma obra literária para um fim a que não estava previamente destinada renova sempre questões sobejamente conhecidas em torno da fidelidade ao original, da reverência ao autor, da inevitabilidade de compressão ou extensão, até da autoridade ou oportunismo de quem se lança nessa aventura. Se, no entanto, a obra a adaptar for tão singular e tão pouco categorizável como Nome de Guerra, de Almada Negreiros, os receios podem dirimir-se por dois motivos: porque a aventura congrega uma equipa "experimentada", a quem se reconhece competência para diagnosticar um objecto apto à cena, operando as devidas alterações; e porque, na presença da primeira condição, e face à genialidade do texto, se pressente que ele pode persistir como outra forma de vida e que seria quase criminoso não o sujeitar a essa virtualidade. Foi esta a confiança que soube resumir depois de ver Exactamente Antunes, a adaptação que Jacinto Lucas Pires fez do romance de Almada Negreiros e que Cristina Carvalhal e Nuno Carinhas conceberam para o Teatro Nacional São João.

0 gozo do espectáculo radica, em primeiro lugar, no que esta versão consegue fazer a partir do texto original: uma sintese vivida, que sublinha o carácter formativo de Nome de Guerra, não desvirtuando, ainda assim, a possivel caracterização da época e dos seus intervenientes. Quer isto dizer que a economia exigivel à versão cénica não quebrou o equilibrio entre as tiradas mais pitorescas, coloquiais, e consequentemente epocais, e as fórmulas e asserções que irrompem em Almada com uma nitidez e um mistério, a um tempo, assinaláveis. Há, pois, a persistência de uma língua falada, ágil e imediata, e de uma língua nova, inteligivel não se sabe bem por que via, actuante no limiar da descoberta. Mas porque essa língua, que é de Almada antes de ser de Antunes, porque esse modo de inocência encriptada provém não só de Nome de Guerra como de palestras, poemas e outros textos do autor, Jacinto Lucas Pires traz o próprio Almada à cena: não o polemista, nem a potência dos manifestos ou das quezilias, antes o orador vibrante, mobilizador, que habita no arco entre a alienação e a visão. As suas aparições estão intimamente ligadas à acção em curso, é enquanto voz autoral que Almada é convocado, pelo que pode instruir tanto o público como as personagens. E a primeira intervenção de A! é exemplar, castiga a desistência de D. Jorge com um murro que, não só reinicia a viagem de Antunes, como parece dar forma a uma tendência de Almada, a de introduzir nos seus textos perturbações gráficas, como a mão imperativa reproduzida no Manifesto anti-Dantas. Sacrificaram-se as descrições e o fino grão de ironia do romance, é certo, mas acrescentou-se ao "espectáculo do homem em luta livre consigo mesmo" a Maria mantida em surdina, aqui personagem de pleno 


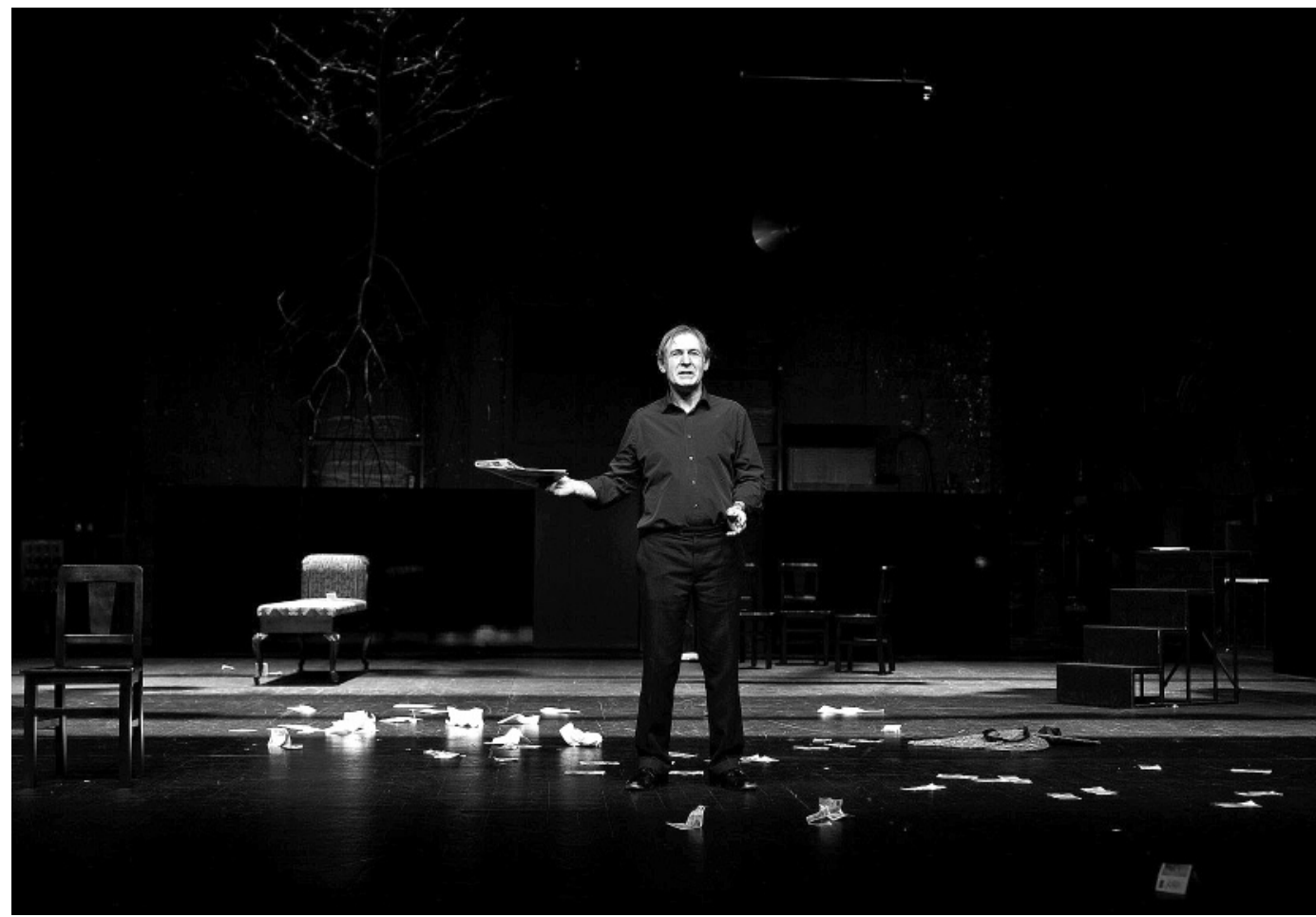

direito, interlocutora das indagações de Antunes e condutora do seu fio de consciência, o que clarifica a equação final "Morreu a Maria, acabou-se a Judite!". Também o Tio é presença bem menos espectral do que suporíamos, e também ele concorre para adensar o transporte da cabeça de Antunes para cena, retesando intenções e expectativas para o sobrinho-por-cumprir, com pompa, farpela e sotaque beirão. Há ainda, nesta versão, um acrescento que é, paradoxalmente, potenciador de irrupções cómicas bastante consensuais e, no conjunto do espectáculo, o mais difícil de assimilar. Servem de base a algumas das canções melodias reconheciveis do pop português, emprestadas de Carlos Paião e António Variações - portuguesíssimas, sem dúvida, assentam que nem uma luva ao tom da prescrição popular, e o anacronismo não seria problema; fica, no entanto, a impressão de que este tipo de cómico, referencial e por isso manifestamente engenhoso, não só não condiz com o restante material, como até trai as estratégias discursivas do autor seminal. É a transparência da piada construida por Jacinto que tende a colidir com a aparência de simplicidade procurada por Almada, choque momentâneo entre um estilo e outro. Mas esta impressão serviria, é claro, uma ampla discussão sobre a visibilidade/invisibilidade do adaptador, que não é pertinente aqui começar.
A responsabilidade do espectáculo, repartida, como já tinha sido dito, por Cristina Carvalhal e Nuno Carinhas, resulta numa primeira colaboração a vários títulos relevante, tanto pela conquista plástica e dramatúrgica, como pelo trabalho de direcção de actores. Cumprem-se globalmente as indicações, abundantes, objectivas, propostas por Jacinto Lucas Pires, mas com uma moderação que resulta lisonjeira para os intérpretes e para o texto, que acredita na sua suficiência. A cena opera a partir do vazio, do negro a toda a profundidade do palco, onde mais recortados aparecem os gestos individuais ou corais. Como opção de fundo, a encenação preferiu as soluções ingénuas, até "escolares", poderia dizer-se (sem ponta de maldade ou juízo de valor, uma vez que me refiro à forma e não à sua execução): que com meia dúzia de cadeiras e uma bandeja se construa a mesa de um clube que depois se transforma em automóvel, aqui, particularmente, foi eureka, como eureka foi de resto a substituição do nu real por fatos de nu, um vestir do nu absolutamente escultórico e

esclarecedor do quanto a ideia da coisa importa mais que a coisa em si. Por outro lado, sentiu-se como bem doseada a alternância entre o retro e o moderno, com a voz de A! a chegar-nos por via de um microfone e altifalante claramente datados, enquanto que certos estados de 


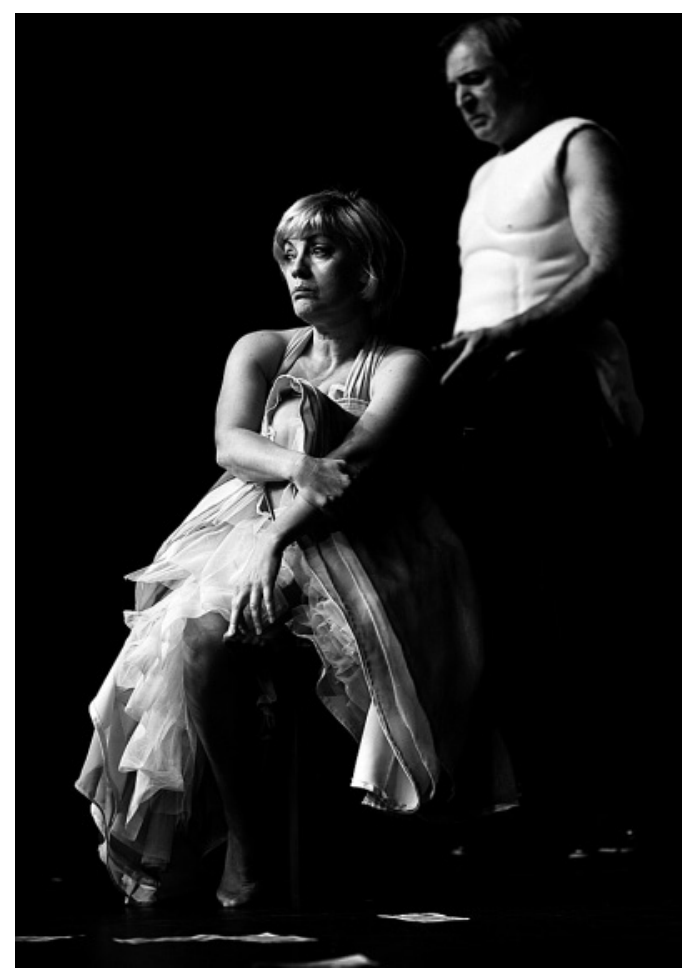

espírito de Antunes, certos títulos de capítulo e lampejos meta-teatrais aparecem num ecrã de legendas, acompanhados pelo som de aviso de mensagem de uma conhecida marca de telemóveis.

Se para Almada "Espectáculo quer dizer Ver!", esta encenação também põe essa necessidade em evidência. Os melhores exemplos disso são, porventura, as interpelações ao universo pictórico de Magritte, na figura do Tio, cuja caracterização remete para o homem do chapéu de coco de Le fils de l'homme e de outros quadros, e na descida da árvore, inteira e com raiz, elemento igualmente recorrente na obra do surrealista belga. É um facto que o trabalho de Nuno Carinhas convoca muitas vezes a pintura à composição da cena. No entanto, estas interpelações revestem-se aqui de um valor que transcende o domínio do referencial e do intelectual, antes actualizam a procura de Almada em torno do que é "constante, universal, sem épocas, sem histórico", "o unânime", portanto, o Sinal, pelo que o seu reconhecimento é secundário, provavelmente avesso a consenso, mas o seu impacto não é de todo negligenciável ou subjectivo. 0 desenho de luz e o desenho de som, discretos se considerados individualmente, funcionam sobretudo como apontamentos rítmicos e atmosféricos, que coincidem

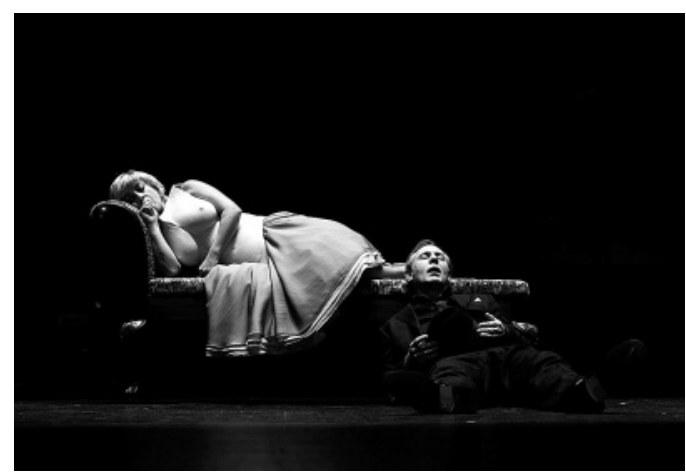

$<>$

Exactamente Antunes de Jacinto Lucas Pires, enc. Cristina Carvalha e Nuno Carinhas, TNSJ, 2011 (Ligia Roque e Jorge Mota), fot. João Tuna. para facilitar a aparição do Sinal. Que o espectáculo procure funcionar a este nível é, creio eu, umas das suas mais generosas ambições.

0 elogio aos actores, que é extensivel ao conjunto do elenco, tem necessariamente de distinguir três intérpretes. Jorge Mota e Ligia Roque, antes de mais, que fizeram de uma distribuição à primeira vista improvável uma vantagem comovente; que aliando, respectivamente, lentidão e ignorância, leveza e lábia, à sua inscrição no mundo, bem mais dilatada que a das suas personagens, aumentaram a acutilância da descoberta. Jorge Mota perfaz a viagem, de Antunes periclitante a Antunes capaz, com um espanto e uma alegria tão púberes quanto genuínos, merecendo inteiramente o protagonista que lhe coube. Juntar a estes nomes o de João Castro é imprescindivel, porque se o Almada performer nos é dado a ver com tanta eficácia é sobretudo culpa sua. Vestido com o fato-macaco que Almada celebrizou em aparições públicas, João Castro teve não só olhos como mãos de gigante, convicção e serenidade que serviram o programa de Almada e produziram um mimetismo surpreendente.

Não exactamente Nome de Guerra, mas Exactamente Antunes, pelo modo como coloca o herói e um certo Almada ingénuo, exactamente, no vórtice da cena, é um espectáculo tanto de sobressaltos como de confirmações, também ele dificilmente categorizável, mas para o qual talvez seja possivel anunciar já a persistência de uma vitória indelével.

\section{Referência filmográfica}

VARELLA, Manuel (1993), Por alma de Negreiros, RTP (telefilme que alterna fragmentos da entrevista de 1968 e reconstituições protagonizadas por Fernando Gomes e Mário Viegas). 